\title{
The Effects of Shoulder Slings on Balance in Patients With Hemiplegic Stroke
}

\author{
Min Kyun Sohn, MD, Sung Ju Jee, MD, Pyoungsik Hwang, MD, Yumi Jeon, MD, Hyunkeun Lee, MD
}

Department of Rehabilitation Medicine, Chungnam National University Hospital, Daejeon, Korea

\begin{abstract}
Objective To investigate the effects of a shoulder sling on balance in patients with hemiplegia.
Methods Twenty-seven hemiplegic stroke patients (right 13, left 14) were enrolled in this study. The subjects' movement in their centers of gravity (COGs) during their static and dynamic balance tests was measured with their eyes open in each sling condition-without a sling, with Bobath's axillary support (Bobath sling), and with a simple arm sling. The percent times in quadrant, overall, anterior/posterior, and medial/lateral stability indexes were measured using a posturography platform (Biodex Balance System SD). Functional balance was evaluated using the Berg Balance Scale and the Trunk Impairment Scale. All balance tests were performed with each sling in random order.

Results The COGs of right hemiplegic stroke patients and all hemiplegic stroke patients shifted to, respectively, the right and posterior quadrants during the static balance test without a sling $(\mathrm{p}<0.05)$. This weight asymmetry pattern did not improve with either the Bobath or the simple arm sling. There was no significant improvement in any stability index during either the static or the dynamic balance tests in any sling condition.

Conclusion The right and posterior deviations of the hemiplegic stroke patients' COGs were maintained during the application of the shoulder slings, and there were no significant effects of the shoulder slings on the patients' balance in the standing still position.
\end{abstract}

Keywords Postural balance, Orthotic devices, Hemiplegia

\section{INTRODUCTION}

Hemiplegia is the most frequent deficit after stroke [1], and hemiplegic stroke patients frequently present bal-

Received April 20, 2015; Accepted June 23, 2015

Corresponding author: Hyunkeun Lee

Department of Rehabilitation Medicine, Chungnam National University Hospital, 282 Munhwa-ro, Jung-gu, Daejeon 35015, Korea

Tel: +82-42-338-2460, Fax: +82-42-338-2461, E-mail: sasijin@cnuh.co.kr

(c) This is an open-access article distributed under the terms of the Creative Commons Attribution Non-Commercial License (http://creativecommons. org/licenses/by-nc/4.0) which permits unrestricted noncommercial use, distribution, and reproduction in any medium, provided the original work is properly cited.

Copyright $\odot 2015$ by Korean Academy of Rehabilitation Medicine ance abnormalities. Balance impairments increase fall risk, resulting in high economic costs and social problems $[2,3]$. Decreased muscle strength, range of movement, abnormal muscle tone, motor coordination, sensory organization, cognition, and multisensory integration can contribute to balance disturbances at different levels [4].

Paralysis of muscles around the shoulder may lead to shoulder subluxation. Shoulder subluxation is a frequent complication for patients with post-stroke hemiplegia [5]. A number of slings with different characteristics, designs, and functions have been used to prevent shoulder subluxation. However, some authors have found slings to be contraindicated $[6,7]$, and only a small number of studies 
have reported on the effects of shoulder slings on balance in hemiplegic patients, and each study has found different results.

Lee et al. [8] reported that Kang's multi-support sling was helpful in reducing weight asymmetry compared with no sling, but postural sway was identical in both the sling and no-sling groups. Acar and Karatas [9] demonstrated that an arm sling had beneficial effects on balance in patients with hemiplegia. However, this study evaluated only static balance and only compared a universal arm sling with no sling.

Studies of task-oriented training showed increased functional outcomes compared with traditional therapies. Active use of task-oriented training with stroke survivors led to improvements in functional outcomes and overall health-related quality of life [10]. However, the simple arm sling on the affected side interrupted taskoriented training in hemiplegic stroke patients. In this respect, the Bobath sling is more beneficial in task-oriented training.

The aim of this study was to investigate and compare the effects of a simple arm sling that restricted upper extremity motion with those of the Bobath sling, which allows free upper extremity motion in both static and dynamic balance. We also investigated weight asymmetry patterns in the static stance position in hemiplegia.

\section{MATERIALS AND METHODS}

\section{Participants}

All participants had been diagnosed with hemiplegic stroke through computed tomography scans or magnetic resonance imaging and met the inclusion criteria of 1) standing without assistive devices for 30 seconds and 2) following the instructions to complete the assessments. We excluded all other factors that could have affected balance; the exclusion criteria were 1) medically unstable, 2) mainly cerebellar lesion, 3) visual impairment or neglect, or 4) neuromusculoskeletal diseases that could affect balance. We also excluded patients who had already experienced the Biodex Balance System for balance training. Twenty-nine participants (Functional Ambulatory Category [FAC], 3.4 \pm 1.1 ; Fugl-Meyer Assessment [FMA] of the affected upper limb, 38 \pm 20 ) met the inclusion criteria and participated in this study with verbal consent. Two of the patients could not finish the dynamic balance test and were thus excluded, ultimately leaving 27 participants in the study.

\section{Methods}

Patients' age, weight, height, side of paretic limb, and time since stroke were recorded, and their neurologic functioning levels-Brunnstrom stage of affected lower limb, FAC, and FMA of affected upper limb-were evaluated (Table 1).

\section{Computerized balance test}

Static and dynamic balance tests were administered using a computerized posturography platform (Biodex Balance System SD; Biodex Medical Systems Inc., Shirley, NY, USA) with eyes open; the balance test with eyes closed was not performed for the subjects' safety. Cachupe et al. [11] reported that in a study of 20 subjects, the Biodex Balance System showed a reliable stability index.

A postural stability test (PST) was used to measure the patients' ability to maintain balance (Fig. 1); PSTs assess balance index scores, which reflect patients' weight asymmetry (\% time in quadrants) and how much they sway in the anterior/posterior and medial/lateral directions. A mean balance index of 3 trials was used for the analysis, and a lower score indicated good balance.

A static balance test was conducted with the participants standing on a fixed circular foot plate and aligning

Table 1. Baseline characteristics of study subjects $(n=27)$

\begin{tabular}{lc}
\hline \multicolumn{1}{c}{ Characteristic } & Value \\
\hline Age $(\mathrm{yr})$ & $57 \pm 12$ \\
\hline Sex (male:female) & $17: 10$ \\
\hline Weight $(\mathrm{kg})$ & $64.9 \pm 12.3$ \\
\hline Height $(\mathrm{cm})$ & $164.2 \pm 9.6$ \\
\hline Body mass index $\left(\mathrm{kg} / \mathrm{m}^{2}\right)$ & $23.9 \pm 3.4$ \\
\hline Stroke subtype (infarction:hemorrhage) & $16: 11$ \\
\hline Hemiplegic side (right:left) & $13: 14$ \\
\hline Time since stroke (wk) & $9.2 \pm 8.2$ \\
\hline Brunnstrom stage of lower limb & $4.5 \pm 0.5$ \\
\hline FAC & $3.4 \pm 1.1$ \\
\hline FMA of upper limb & $38 \pm 20$ \\
\hline
\end{tabular}

Values are presented as mean \pm standard deviation or number.

FAC, Functional Ambulation Category; FMA, Fugl-Meyer Assessment. 


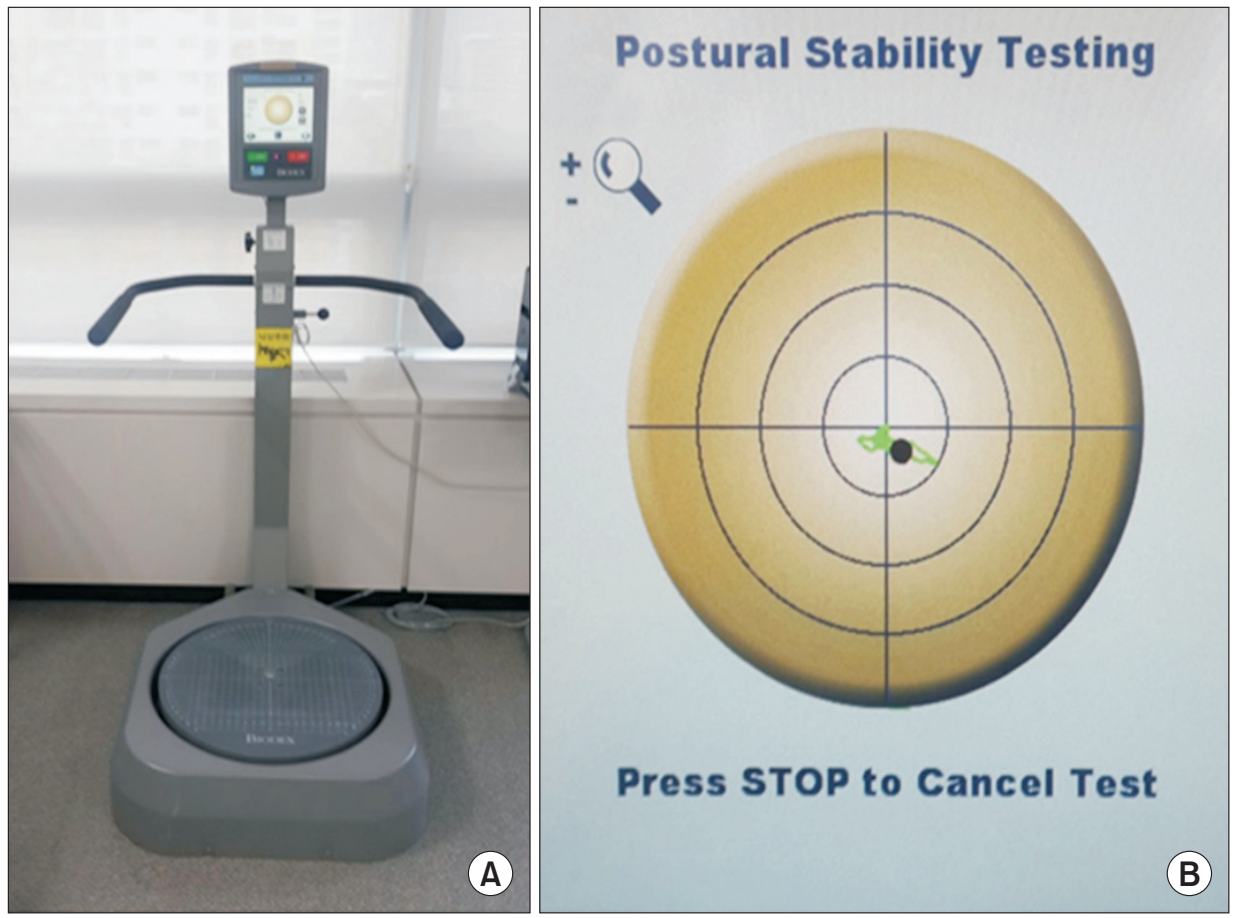

Fig. 1. (A) Biodex Balance System SD (Biodex Medical Systems Inc., Shirley, NY, USA) and (B) screen of Biodex Balance System SD during a postural stability test. their centers of gravity (COGs) to the center of the circular plate as shown on the monitor. Dynamic balance involved free tilting of the circular foot plate depending upon weight shifting, and the static force was set to Stage 6 of 12 stages.

Body weight shifts were traced in a green line on the model plate, which was divided into quadrants, and the time durations spent in each zone were indicated as percentages (\% time). Each distance of the overall, anterior/ posterior, and medial/lateral body weight shifts was also measured. The results were recorded as the overall stability index (overall index), the anterior/posterior stability score (AP index), and the medial/lateral stability index (ML index). The AP index represents the variance in platform displacement, in degrees, for motion in the sagittal plane. The ML index represents the variance in platform displacement for motion in the frontal plane, and the overall index was determined based on the AP and ML indices.

\section{Functional balance test}

The functional balance test used the Berg Balance Scale (BBS) and the Trunk Impairment Scale (TIS) $[12,13]$. The BBS is a widely used clinical test of static and dynamic balance [14], and it is generally considered to be the gold standard for functional balance tests. The scale takes 15-20 minutes and comprises a set of 14 simple balance-related tasks ranging from standing up from a sitting position to standing on one foot. The success in achieving each task is rated from zero (unable) to four (independent), and the final measure is the sum of all of the scores. Considerable evidence indicates that the BBS is also a valid measure of standing balance in post-stroke patients, but only for those who ambulate independently, because of the tasks that are required of the patients [15]. The TIS consists of three subscales: static sitting balance, dynamic sitting balance, and coordination, and each subscale contains between three and ten items. The TIS score ranges from a minimum of 0 to a maximum of 23 .

\section{Outcome measures}

All balance tests including computerized and functional tests were conducted in each three sling conditions: without a sling, with the Bobath sling, and with a simple arm sling (Fig. 2), and each were performed in random order of sling condition to eliminate learning effects within 40 minutes.

\section{Statistical analysis}

All statistical analyses were performed using SPSS ver. 18 for Windows (SPSS Inc., Chicago, IL, USA). The quadrant and half-plane distributions were analyzed by paired 

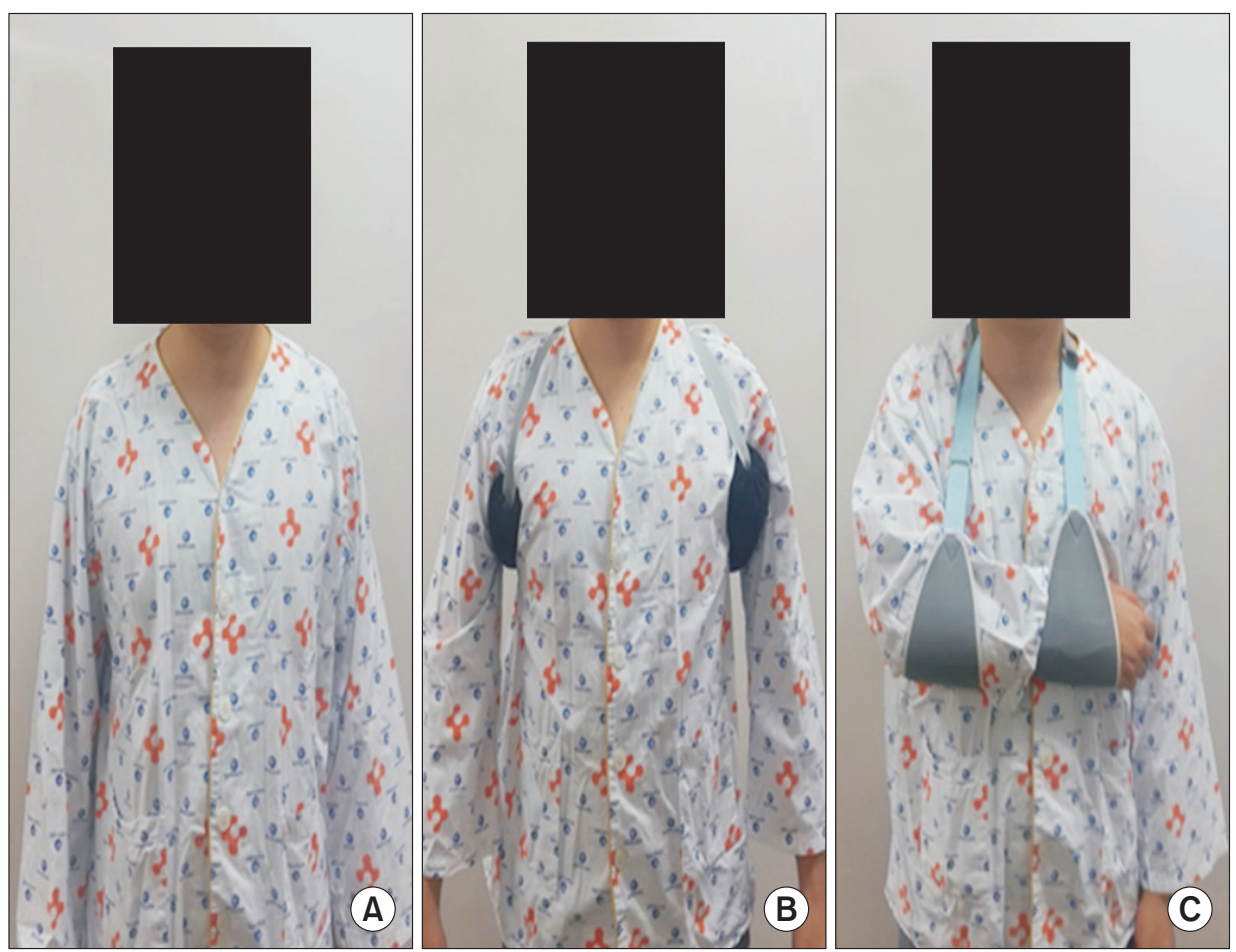

Fig. 2. The three balance measuring positions: (A) no sling, (B) Bobath sling, and (C) simple arm sling.
(A)

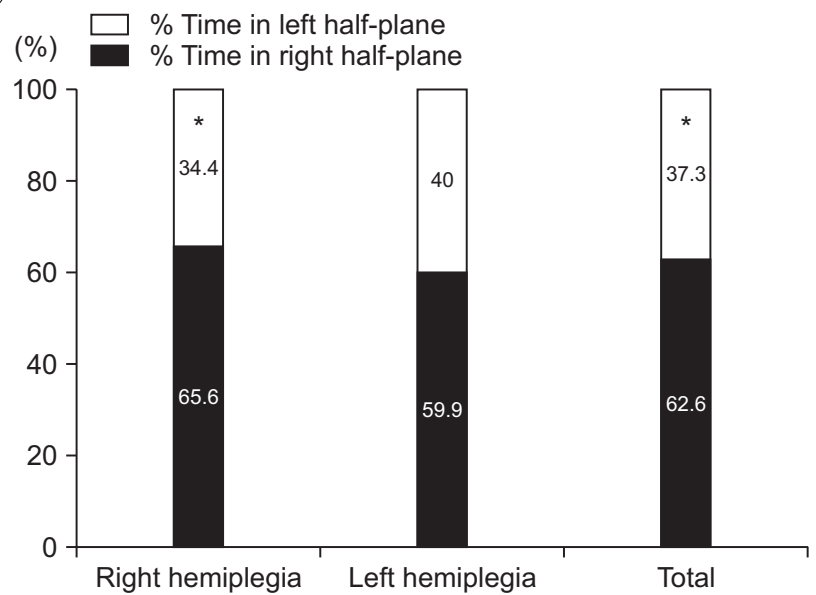

(B)

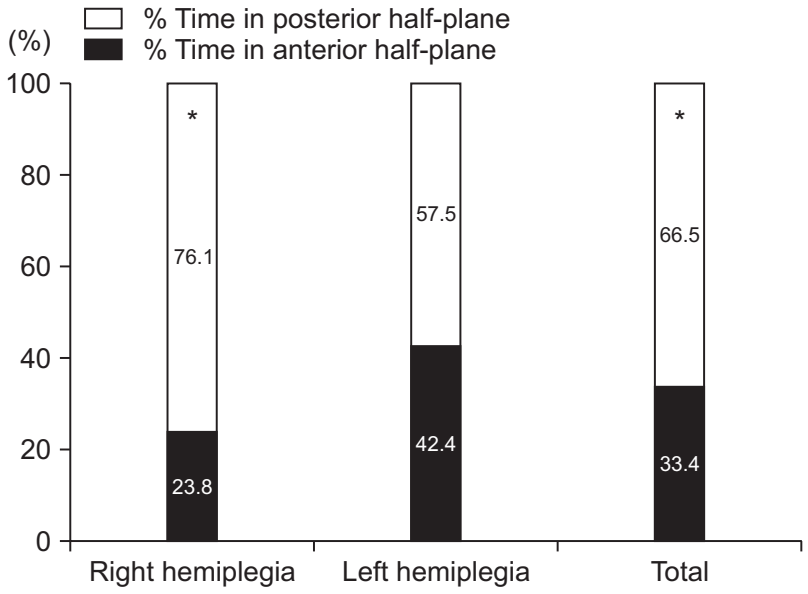

Fig. 3. The percent time pattern in half-plane without sling on the static balance test. The center of gravity was asymmetrically distributed to the right half-plane in the total group and in the right hemiplegia subgroup (A) and to the posterior half-plane in the total group and in the right hemiplegia subgroup (B). ${ }^{*} p<0.05$, significant difference between right and left half-planes (A), and between anterior and posterior half-planes (B).

t-test. Repeated-measures analysis of variance (ANOVA) was used to compare the balance index (overall, AP, and ML indices) and functional balance scores for each of the three sling conditions (i.e., no sling, Bobath sling, and simple arm sling). Pearson and Spearman correlation coefficients were calculated to analyze the relationships between the balance tests and the upper extremity FAC and FMA values. Data are presented as mean \pm standard deviation in the tables or as standard error in the figures. Statistical significance was accepted at a $\mathrm{p}<0.05$. 
(A)

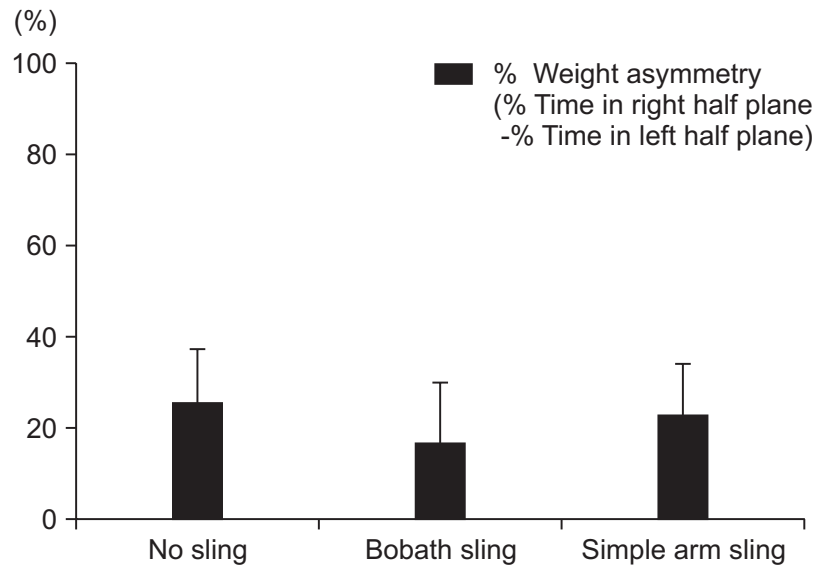

(B)

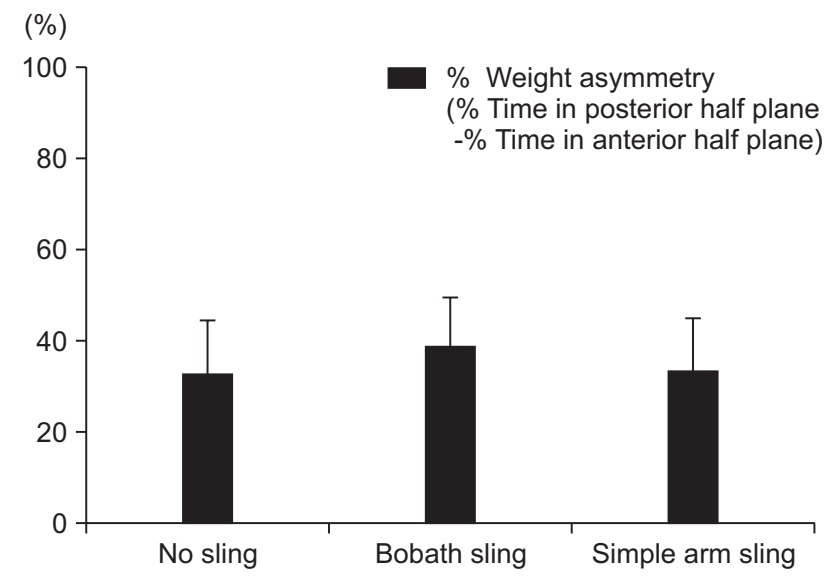

Fig. 4. Weight asymmetry (\%) between the half-planes of the total group in each sling condition on static balance test (mean \pm standard error). The center of gravity asymmetry pattern did not improve in either sling condition between the right and left half-planes (A) or the anterior and posterior half-planes (B).

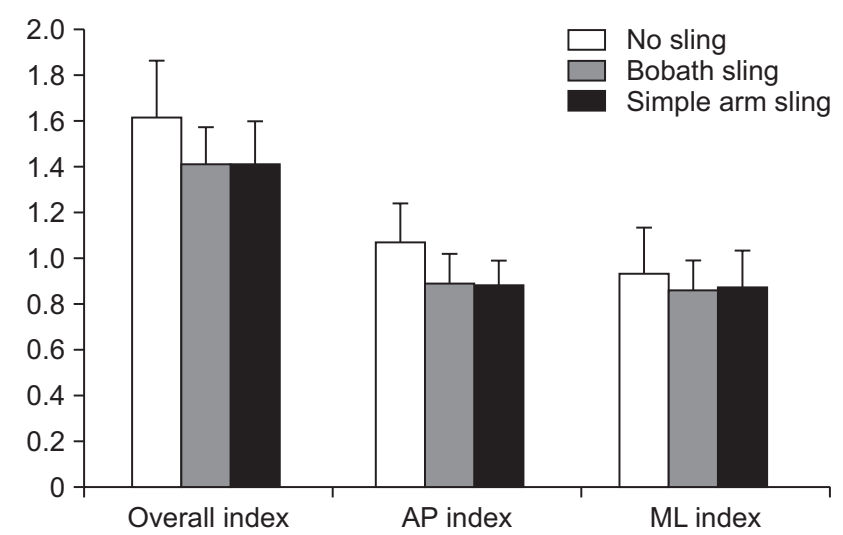

Fig. 5. The overall, AP, and ML static balance index scores in each sling condition (mean \pm standard error). There was no significant changes in any of the scores between any of the sling conditions. AP, anterior-posterior; ML, medial-lateral.

\section{RESULTS}

\section{\% Time in half-plane of hemiplegic stroke patients}

On the static balance test without a sling, the right hemiplegic group showed COG asymmetry of the right and posterior half-planes $(\mathrm{p}<0.05)$, and these asymmetry patterns were also maintained in the left hemiplegic subjects but without statistical significance (Fig. 3). The weight asymmetry (\%) of the total group between the right and left half-planes was not significantly improved with either the Bobath sling or the simple arm sling (no sling 25.2 \pm 61.6 , Bobath sling 16.7 \pm 68.4 , simple arm sling,

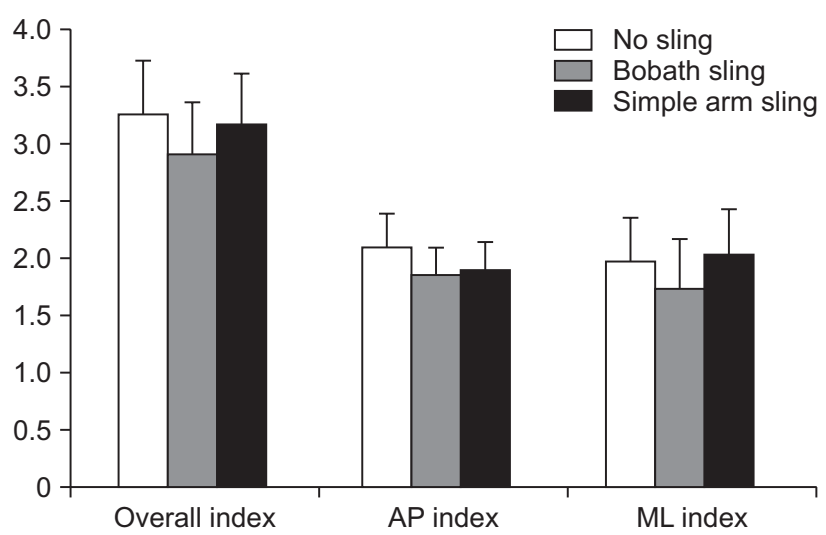

Fig. 6. The overall, AP, and ML dynamic balance index scores in each sling condition (mean \pm standard error). There were no significant changes in any of the scores between any of the sling conditions. AP, anterior-posterior; ML, medial-lateral.

22.8 $\pm 57.9 ; \mathrm{F}=0.525, \mathrm{p}=0.563)$. Additionally, the weight asymmetry (\%) of the total group between the posterior and anterior half-planes was not significantly improved with either the Bobath or the simple arm sling (no sling $33.0 \pm 60.2$, Bobath sling $39.2 \pm 54.3$, simple arm sling $34.0 \pm 56.9 ; \mathrm{F}=0.372$, $\mathrm{p}=0.685$ ) (Fig. 4). After the application of each sling, there was no significant change in the rightposterior deviation of COG distribution during the static balance test.

\section{Static and dynamic balance in each sling condition}

There was no significant improvement in the overall 
Table 2. Functional balance test results in each sling condition

\begin{tabular}{lccccc}
\hline & $\begin{array}{c}\text { No } \\
\text { sling }\end{array}$ & $\begin{array}{c}\text { Bobath } \\
\text { sling }\end{array}$ & $\begin{array}{c}\text { Simple } \\
\text { arm sling }\end{array}$ & F & p-value $^{\text {a) }}$ \\
\hline BBS & $46.4 \pm 10.3$ & $46.4 \pm 10.7$ & $46.6 \pm 10.3$ & 0.471 & 0.596 \\
TIS & $19.4 \pm 3.4$ & $19.7 \pm 2.8$ & $19.6 \pm 2.9$ & 0.107 & 0.526 \\
\hline
\end{tabular}

Values are presented as mean \pm standard deviation or number.

BBS, Berg Balance Scale; TIS, Trunk Impairment Scale.

${ }^{\text {a) }}$ Repeated-measures ANOVA.

Table 3. Correlation analysis between FAC and balance test in each sling condition

\begin{tabular}{lccc}
\hline \multirow{2}{*}{ Balance test } & \multicolumn{3}{c}{ FAC } \\
\cline { 2 - 4 } & $\begin{array}{c}\text { No } \\
\text { sling }\end{array}$ & $\begin{array}{c}\text { Bobath } \\
\text { sling }\end{array}$ & $\begin{array}{c}\text { Simple } \\
\text { arm sling }\end{array}$ \\
\hline Static overall BI & $-0.562^{*}$ & $-0.553^{*}$ & $-0.609^{*}$ \\
Dynamic overall BI & $-0.506^{*}$ & $-0.568^{*}$ & $-0.592^{*}$ \\
BBS & $0.693^{*}$ & $0.695^{*}$ & $0.697^{*}$ \\
TIS & $0.641^{*}$ & $0.694^{*}$ & $0.648^{*}$ \\
\hline
\end{tabular}

Values are correlation coefficients.

BI, balance index; FAC, Functional Ambulation Category; BBS, Berg Balance Scale; TIS, Trunk Impairment Scale.

${ }^{*}$ Correlation is significant at the 0.01 level.

static index (no sling 1.61 \pm 1.31 , Bobath sling $1.41 \pm 0.87$, simple arm sling $1.41 \pm 1.02 ; \mathrm{F}=1.33, \mathrm{p}=0.273)$, the ML index (no sling $0.93 \pm 1.06$, Bobath sling $0.86 \pm 0.68$, simple arm sling $0.87 \pm 0.86 ; \mathrm{F}=0.187, \mathrm{p}=0.781$ ), or the AP index (no sling $1.07 \pm 0.90$, Bobath sling $0.89 \pm 0.68$, simple arm sling $0.88 \pm 1.02 ; \mathrm{F}=1.482, \mathrm{p}=0.238$ ) with the use of any sling compared with no sling (Fig. 5).

There was no significant improvement in the overall dynamic index (no sling 3.26 \pm 2.46 , Bobath sling 2.91 \pm 2.43 , simple arm sling $3.17 \pm 2.35 ; \mathrm{F}=1.627, \mathrm{p}=0.208$ ), the $\mathrm{ML}$ index (no sling 1.97 \pm 2.06 , Bobath sling 1.74 \pm 2.24 , simple arm sling 2.03 $\pm 2.12 ; \mathrm{F}=1.912, \mathrm{p}=0.165)$, or the AP index (no sling 2.10 \pm 1.52 , Bobath sling $1.86 \pm 1.22$, simple arm sling $1.90 \pm 1.27 ; \mathrm{F}=1.48, \mathrm{p}=0.237$ ) with the use of any sling compared with no sling (Fig. 6).

\section{Functional balance test}

There were no significant differences in BBS scores (no sling 46.4 \pm 10.3 , Bobath sling 46.4 \pm 10.7 , simple arm sling 46.6 $\pm 10.3 ; \mathrm{F}=0.471, \mathrm{p}=0.596$ ) or TIS scores (no sling 19.4 \pm 3.4 , Bobath sling $19.7 \pm 2.8$, simple arm sling
Table 4. Correlation analysis between FMA of upper limbs and balance tests in each sling condition

\begin{tabular}{lccc}
\hline \multirow{2}{*}{ Balance test } & \multicolumn{3}{c}{ FMA of upper limb } \\
\cline { 2 - 4 } & $\begin{array}{c}\text { No } \\
\text { sling }\end{array}$ & $\begin{array}{c}\text { Bobath } \\
\text { sling }\end{array}$ & $\begin{array}{c}\text { Simple } \\
\text { arm sling }\end{array}$ \\
\hline Static overall BI & -0.265 & -0.252 & -0.218 \\
Dynamic overall BI & $-0.485^{*}$ & $-0.565^{*}$ & $-0.489^{*}$ \\
BBS & $0.486^{*}$ & $0.491^{*}$ & $0.486^{*}$ \\
TIS & $0.608^{*}$ & $0.656^{*}$ & $0.642^{*}$ \\
\hline
\end{tabular}

Values are correlation coefficients.

BI, balance index; FMA, Fugl-Meyer Assessment; BBS, Berg Balance Scale; TIS, Trunk Impairment Scale. ${ }^{*}$ Correlation is significant at the 0.01 level.

19.6 $\pm 2.9 ; \mathrm{F}=0.107, \mathrm{p}=0.526$ ) between the sling conditions (Table 2).

\section{Correlation analysis}

All balance tests were correlated with FAC $(\mathrm{p}<0.01)$. FMAs of the affected upper limbs were correlated with dynamic balance index, BBS and TIS scores but not with static balance index scores. The correlation coefficients are displayed in Tables 3 and 4 .

\section{DISCUSSION}

The goal of this study was to evaluate the effects of a shoulder sling on balance in patients with hemiplegia. The results demonstrated that neither a simple arm sling nor the Bobath sling affected either the static or the dynamic balance tests.

Balance is the ability to maintain a body's line of gravity within its support base with minimal postural sway [16], and sway is the horizontal movement of the COG even when a person is standing still [17]. Balance can be understood as the ability to keep the COG within the limits of the support base, or stability limits; these limits are not fixed but, rather, can be modified according to tasks, movements, individual biomechanics, and environmental aspects [18].

Hyndman et al. [19] found that upper limb motor function was significantly reduced in patients with a history of recurring falls. Concerning the effect of balance in recurrent falls, it could be proposed that balance in patients with reduced arm function is impaired. It has also been shown that motor impairment of the upper ex- 
tremities affects the independent ambulation of patients with hemiplegia [20]. Some researchers reported that restraining the upper arm increased the arm swing on the opposite side in order to maintain the coordination between upper and lower body movement [21,22]. Using arm slings while standing may be recommended because of the beneficial effects on subluxation in patients who have a flaccid arm and subluxation [9]. A few studies have assessed the efficacy of slings in reducing shoulder subluxation. However, some authors report that some slings facilitate increased flexor tone and synergistic patterns, cause reflex sympathetic dystrophy, restrain functional recovery, obstruct arm swing during walking, and, for some, impair body image $[6,7]$.

Lee et al. [8] reported that Kang's multi-support sling was helpful in reducing weight asymmetry compared with both no sling and a cuff-type sling because arm slings help patients to become aware of their upper limbs and body posture owing to the slings' wide contact area with the body. However, weight asymmetry patterns did not change with the use of any arm sling in our study. The simple arm sling that we used was similar to the cufftype sling in shape and contact area, and meanwhile, the subjects' affected upper limbs did not show close contact with the Bobath sling in the standing posture. The differences in contact area width of each arm sling could have affected weight asymmetry patterns. However, the Bobath and simple arm slings that were used in our study have extremely different contact area widths and body contact points, yet there were no significant differences in weight asymmetry between the two sling conditions.

Nichols [23] reported that in addition to weight shifting, increased postural sway is another important feature of balance problems in patients with hemiplegia. Lee et al. [8] reported that Kang's multi-support sling had no effect on postural sway. Acar and Karatas [9] demonstrated that the COG excursion was greater for patients with hemiplegia than it was for normal persons and that it decreased with the use of an arm sling. The authors explained that the better results could have been attributable to the inhibited abnormal arm-trunk patterns. The aforementioned studies reported different results for postural sway changes after arm sling application in hemiplegic patients, but in this study, balance index did not improve with the use of shoulder slings. The difference could be a consequence of the study groups' characteristics (mean BBS is 45 in this study; mean BBS is 29 in Acar and Karatas [9]); in that study, only hemiplegic patients with shoulder subluxation were included. In addition, each study's authors used different devices to measure balance index.

Yavuzer and Ergin [24] reported the effects of an arm sling on gait patterns in hemiplegia with a quantitative gait analysis system. With the use of an arm sling, walking speed increased, COG excursion decreased, and weightbearing on the paretic side increased. Those authors measured maximal pelvic excursion in the sagittal, coronal, and transverse planes and the peak vertical force on the paretic sides during subjects' gait cycles. However, for the subjects in the current study, COG was measured while patients stood still in the center of a circular plate as shown on a monitor, and this difference could have led to different results. Based on the results from both our study and those mentioned above, we suggest that arm slings affect peak vertical force in the paretic limb when walking but perhaps not while standing still.

This study showed right posterior COG deviation in right hemiplegic stroke patients but no significant weight asymmetry in the left-side group. That is, weight shift in the hemiplegic patients towards the non-affected side was inconsistent. These results are different from those of a study that demonstrated weight shift toward the unaffected extremity [25]. It can be concluded that whereas those authors measured maximum voluntary weightbearing on both the affected and unaffected legs, our study measured weight asymmetry patterns in a neutral standing position. Sohn et al. [26] reported that COGs in healthy right-handed adults shifted to the right posterior quadrant. As in that study, our study found that right hemiplegic patients still showed right posterior deviation in their COGs and that this deviation remained with all slings. However, the left hemiplegic group decreased in weight asymmetry. The mechanism of the right posterior COG was not clear in this study in that the dominant hand side and other factors might have affected weight shift patterns. Additional studies will be needed to clarify the exact mechanisms.

In this study, FMAs in the affected upper extremities correlated with dynamic balance index, BBS and TIS scores but not with the static balance index. Wassinger et al. [27] reported that upper body fatigue had adverse effects on dynamic standing balance, and generally, stand- 
ing balance decreases following upper extremity or generalized fatiguing exercises such as trunk isokinetics or squat thrusts [28]. Thus, clinicians should be aware of the adverse effects of upper extremity weakness on dynamic standing balance. We concluded that upper extremities may be important in balance in more dynamic conditions.

There are a number of limitations in our study. First, the presence of shoulder subluxation was not evaluated initially, but there are certain problems associated with balance testing in hemiplegic patients both with and without shoulder subluxation. Second, we reported that shoulder slings had no effects on balance in hemiplegic stroke patients, but these results can only be generalized to patients with mild to moderate hemiparesis. Third, the dominant hand side can affect weight shifting patterns, but we did not assess the dominant hand side at the beginning of the study. Fourth, we did not assess dynamic balance during gait (e.g., Timed Up and Go test) by sling type.

In conclusion, there were no significant improvements with the use of two different types of slings on balance or on right posterior deviation in the COGs of hemiplegic patients in the standing still position. Because the present study was conducted for a short period, these results cannot be generalized without additional studies on long-term effects.

\section{CONFLICT OF INTEREST}

No potential conflict of interest relevant to this article was reported.

\section{ACKNOWLEDGMENTS}

This work was supported by the research fund of the Chungnam National University.

\section{REFERENCES}

1. Gresham GE, Duncan PW, Stason WB, Adams HP, Adelman AM, Alexander DM, et al. Post-stroke rehabilitation: assessment, referral, and patient management: quick reference guide for clinicians. J Geriatr Drug Ther 1996;11:7-44.

2. Lamb SE, Ferrucci L, Volapto S, Fried LP, Guralnik JM;
Women's Health and Aging Study. Risk factors for falling in home-dwelling older women with stroke: the Women's Health and Aging Study. Stroke 2003;34:494501.

3. Chen IC, Cheng PT, Hu AL, Liaw MY, Chen LR, Hong $\mathrm{WH}$, et al. Balance evaluation in hemiplegic stroke patients. Chang Gung Med J 2000;23:339-47.

4. Bonan IV, Colle FM, Guichard JP, Vicaut E, Eisenfisz M, Tran Ba Huy P, et al. Reliance on visual information after stroke. Part I: Balance on dynamic posturography. Arch Phys Med Rehabil 2004;85:268-73.

5. Paci M, Nannetti L, Rinaldi LA. Glenohumeral subluxation in hemiplegia: an overview. J Rehabil Res Dev 2005;42:557-68.

6. Turner-Stokes L, Jackson D. Shoulder pain after stroke: a review of the evidence base to inform the development of an integrated care pathway. Clin Rehabil 2002;16:276-98.

7. Zorowitz RD, Idank D, Ikai T, Hughes MB, Johnston MV. Shoulder subluxation after stroke: a comparison of four supports. Arch Phys Med Rehabil 1995;76:76371.

8. Lee DK, Han SJ, Yoon SI, Kim MJ, Lee KH. Effect of arm sling on standing balance of hemiplegic patients. J Korean Acad Rehabil Med 2004;28:532-6.

9. Acar M, Karatas GK. The effect of arm sling on balance in patients with hemiplegia. Gait Posture 2010;32:641-4.

10. Rensink M, Schuurmans M, Lindeman E, Hafsteinsdottir T. Task-oriented training in rehabilitation after stroke: systematic review. J Adv Nurs 2009;65:737-54.

11. Cachupe WJ, Shifflett B, Kahanov L, Wughalter EH. Reliability of biodex balance system measures. Meas Phys Educ Exerc Sci 2001;5:97-108.

12. Berg K, Wood-Dauphine S, Williams JI, Gayton D. Measuring balance in the elderly: preliminary development of an instrument. Physiother Can 1989;41: 304-11.

13. Verheyden G, Nieuwboer A, Mertin J, Preger R, Kiekens $\mathrm{C}$, De Weerdt W. The Trunk Impairment Scale: a new tool to measure motor impairment of the trunk after stroke. Clin Rehabil 2004;18:326-34.

14. Blum L, Korner-Bitensky N. Usefulness of the Berg Balance Scale in stroke rehabilitation: a systematic review. Phys Ther 2008;88:559-66.

15. Stevenson TJ. Detecting change in patients with stroke using the Berg Balance Scale. Aust J Physiother 
2001;47:29-38.

16. Shumway-Cook A, Anson D, Haller S. Postural sway biofeedback: its effect on reestablishing stance stability in hemiplegic patients. Arch Phys Med Rehabil 1988;69:395-400.

17. Davidson BS, Madigan ML, Nussbaum MA. Effects of lumbar extensor fatigue and fatigue rate on postural sway. Eur J Appl Physiol 2004;93:183-9.

18. de Oliveira CB, de Medeiros IR, Frota NA, Greters ME, Conforto AB. Balance control in hemiparetic stroke patients: main tools for evaluation. J Rehabil Res Dev 2008;45:1215-26.

19. Hyndman D, Ashburn A, Stack E. Fall events among people with stroke living in the community: circumstances of falls and characteristics of fallers. Arch Phys Med Rehabil 2002;83:165-70.

20. Au-Yeung SS, Ng JT, Lo SK. Does balance or motor impairment of limbs discriminate the ambulatory status of stroke survivors? Am J Phys Med Rehabil 2003;82:279-83.

21. Marks R. The effect of restricting arm swing during normal locomotion. Biomed Sci Instrum 1997;33:209-15.
22. Ford MP, Wagenaar RC, Newell KM. Arm constraint and walking in healthy adults. Gait Posture 2007; 26:135-41.

23. Nichols DS. Balance retraining after stroke using force platform biofeedback. Phys Ther 1997;77:553-8.

24. Yavuzer G, Ergin S. Effect of an arm sling on gait pattern in patients with hemiplegia. Arch Phys Med Rehabil 2002;83:960-3.

25. Goldie PA, Matyas TA, Evans OM, Galea M, Bach TM. Maximum voluntary weight-bearing by the affected and unaffected legs in standing following stroke. Clin Biomech (Bristol, Avon) 1996;11:333-42.

26. Sohn MK, Lee SS, Song HT. Effects of acute low back pain on postural control. Ann Rehabil Med 2013; 37:17-25.

27. Wassinger CA, McKinney H, Roane S, Davenport MJ, Owens B, Breese U, et al. The influence of upper body fatigue on dynamic standing balance. Int J Sports Phys Ther 2014;9:40-6.

28. Cetin N, Bayramoglu M, Aytar A, Surenkok O, Yemisci OU. Effects of lower-extremity and trunk muscle fatigue on balance. Open Sports Med J 2008;2:16-22. 